\title{
A MOOC with a Business Plan
}

\section{Mr. Eugene Rutz, University of Cincinnati}

Academic Director in the College of Engineering \& Applied Science with academic and administrative oversight of distance learning programs, combined degree programs and high school dual enrollment. Experience as educator, practicing engineer and educational researcher.

\section{Jim Tappel, University of Cincinnati}

Dr. BJ Zirger, University of Cincinnati 


\section{A MOOC With A Business Plan}

\section{Background}

In the short time that Massive Open Online Courses (MOOCs) have been part of the education landscape, they have generated significant enrollments, much media attention, several high profile startups, and a lot of discussion regarding their role in higher education. ${ }^{1-4}$ One of the many questions about MOOCs that has not yet been answered completely is how to justify the expense of creating such a course. A related question that likewise has no clear answer is whether an appropriate business model $^{5}$ can be implemented that utilizes MOOCs as an educational platform.

Before rushing to develop a MOOC, the University of Cincinnati considered these and other questions. Recognizing that offering a course with a potential enrollment of thousands of students presented challenges (and opportunities) that the University had not faced before, a clear strategy was necessary to guide the development and implementation of this effort.

This paper describes the strategy adopted at the University of Cincinnati as well as pragmatic considerations for developing the MOOC. The paper also discusses the implementation of the MOOC and results in terms of the business model and student persistence. Lessons learned are presented so that other universities can benefit from our experiences.

\section{Strategy and Business Plan}

The University of Cincinnati has a number of online programs in various colleges and significant experience in developing and managing online courses. The College of Engineering \& Applied Science and the Lindner College of Business had both launched new online degree programs within the year and both were interested in gaining experience with MOOCs. There is a history of academic collaboration between the two colleges ${ }^{6}$ and both work with a third party, Academic Partnerships, on instructional design, strategic planning, and enrollment management.

In consultation with the Provost's Office the colleges adopted this approach to the MOOC:

- The course topic would be appropriate for both the MBA degree and the Master of Engineering degree programs.

- The course would be collaboratively developed between the colleges and faculty from both colleges would participate.

- The course would be offered in a half-semester format consistent with courses in the online degree programs.

- The course would be free and open to anyone who wanted to participate.

While the course was open to anyone, the content creation and course experiences would be developed so that the course would be appropriate for a graduate program. The Colleges adopted a "MOOC to Degree" strategy wherein individuals who successfully met course learning outcomes at a competency of $75 \%$ or better on the module quizzes and who then matriculated into either the MBA or Master of Engineering program could receive credit for the course. Students would be required to successfully complete two traditional courses before credit for the 
MOOC would be awarded and students would need to further demonstrate attainment of course learning outcomes before receiving credit.

The basic business model is illustrated in Table 1. The administrative support accounts for time spent by the two primary administrative representatives from the colleges; it does not account for support provided by other administrative units such as IT, the Provost's Office, Office of Public Relations and others.

Table 1 Characteristics of MOOC Business Model

\begin{tabular}{|r|r|}
\hline Expenses & Amount \\
\hline MOOC Development & \\
Faculty Compensation & \\
Grad Student & \\
Administrative & $\$ 10,000$ \\
\cline { 2 - 2 } Videography & $\$ 3,000$ \\
\cline { 2 - 2 } Marketing & $\$ 20,000$ \\
\cline { 2 - 2 } & $\$ 2,000$ \\
\hline MOOC Offering & $\$ 6,000$ \\
Faculty Compensation & \\
Facilitators & \\
\cline { 2 - 2 } Grad Student & $\$ 15,000$ \\
\cline { 2 - 2 } Administrative & $\$ 4,000$ \\
Total & $\$ 3,000$ \\
\hline & $\$ 10,000$ \\
\hline & $\$ 73,000$ \\
\hline Income & \\
\hline Engineering Student & $\$ 21,500$ \\
\hline Business Student & $\$ 29,850$ \\
\hline
\end{tabular}

The total expenses listed in Table 1 are for the development and first offering of the MOOC. The income listed is the amount that would be generated by a student in one of the degree programs (with no charge for the credits earned through the MOOC). The costs would be recouped if 3 students matriculate into degree programs as a result of participation in the MOOC.

\section{Course Description and Development}

Individuals responsible for directing distance learning efforts in the College of Business and the College of Engineering \& Applied Science first worked to determine an appropriate topic that would fit degree programs in both Colleges. Several choices were discussed and the topic Innovation and Design Thinking was selected for several reasons: it was an important topic to degree programs in both Colleges, there were faculty in both colleges who are well regarded who teach and have experience in the subject area, the topic lent itself to an online format, and a number of other MOOCS with complimentary themes were also being offered by other universities. 
The development team consisted of a faculty member from each college, distance learning administration from each college, a graduate student familiar with online learning, and representatives from Academic Partnerships familiar with instructional design and student support. The team initially met in person for several meetings then moved to a weekly conference call to coordinate efforts and resolve issues. Basecamp was used as an online platform to manage communication, document exchange, schedule and discussions among the development team.

The development team researched platforms to use for hosting the MOOC. Since Blackboard is used by the University as the learning management system, CourseSites (see Coursesites.com) was selected as the MOOC platform. CourseSites also had no costs associated with its use and provided adequate technical support, both significant factors for a first effort in this area.

The course was developed around several unifying concepts. The first was the spiral model of new product development as illustrated in Figure 1. Course materials were developed and presented using this model to frame the topics and build competencies. The second was the idea that students would use what they learned through the course and in each module on a project of practical importance to them.

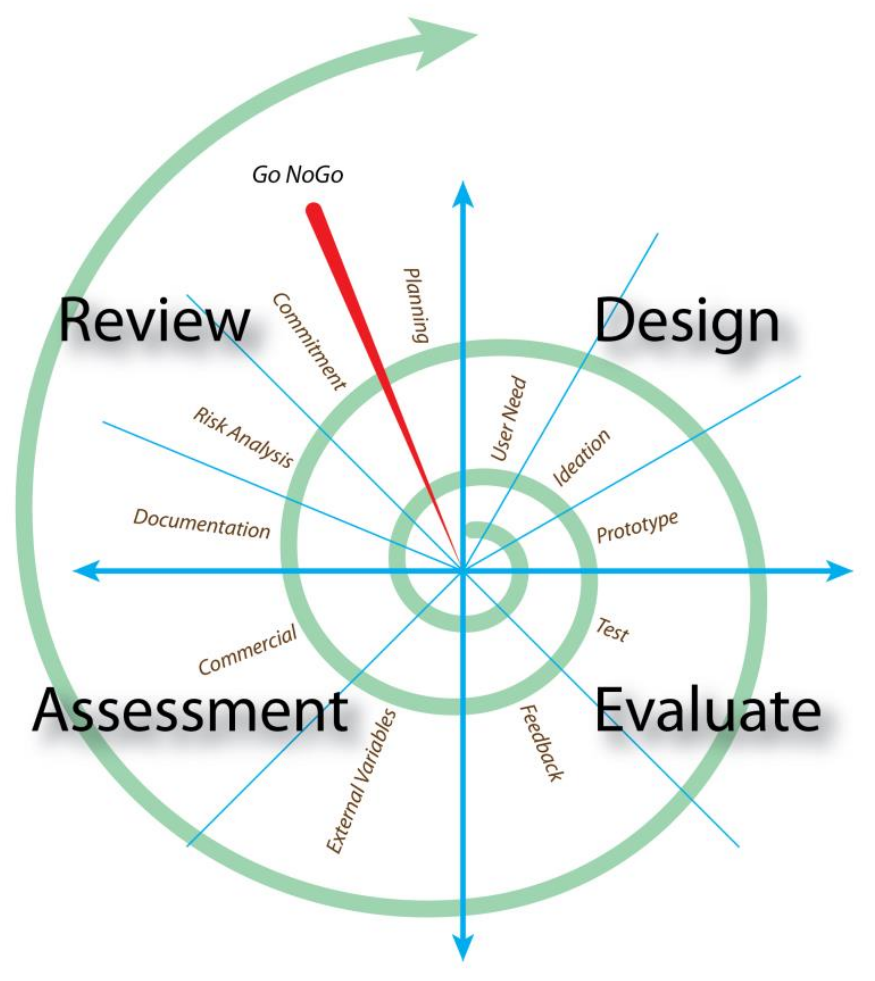

Figure 1 Spiral Development Model

The course was offered over a 7 week time frame with each week addressing a module of content. Each module contained four short presentations, reading materials, exercises, and a video featuring practitioners in the topic areas. Each week also had discussion topics posted by 
the instructors and a quiz to assess student achievement of learning outcomes. Learning outcomes and tasks for the week were clearly articulated for each module.

The faculty each developed two narrated PowerPoint presentations for each module. These were edited as needed and uploaded to both CourseSites and Vimeo (see vimeo.com) for ease of playback. The faculty also selected the readings for each module and developed the exercises to be completed. The faculty formulated questions for the quizzes which the graduate student used to create weekly quizzes using Respondus (see respondus.com).

Five individuals with significant experience with innovation, new product development and business start-up provided the "voice of the practitioner" segment for each module. These segments reinforced the topics presented and illustrated the significance of the concepts to products, services and organizations.

Facilitators were used to monitor the discussions so that faculty did not need to spend significant time in this activity ${ }^{7}$. The primary role of the facilitators was to provide frequent interactions with students and engage them in the course topics. They also "policed" the discussions to remove inappropriate or off-topic comments.

\section{MOOC Implementation}

The course was offered from October 7 to November 22, 2013 though the course remained open until December 2, 2013. The MOOC drew over 2,500 participants from 90 countries. Table 2 presents information from participants responding to the md-course survey

Table 2 Student Characteristics

\begin{tabular}{|l|c|l|c|l|c|}
\hline \multicolumn{3}{|c|}{ Occupation } & \multicolumn{2}{c|}{ Age } & \multicolumn{2}{c|}{ Education } \\
\hline Professional & $43 \%$ & $21-24$ & $2 \%$ & Completed High School & $36 \%$ \\
\hline White Collar & $18 \%$ & $25-34$ & $26 \%$ & Attended College & $1 \%$ \\
\hline Middle Management & $11 \%$ & $35-44$ & $25 \%$ & Completed College & $40 \%$ \\
\hline Blue Collar & $10 \%$ & $45-54$ & $28 \%$ & Completed Grad School & $22 \%$ \\
\hline Student & $4 \%$ & $55-64$ & $15 \%$ & & \\
\hline Retired & $4 \%$ & $65+$ & $3 \%$ & & \\
\hline Other & $10 \%$ & & & & \\
\hline
\end{tabular}

Figure 2 presents participants responses to the survey question "What is your reason for taking this course?" Participants could select more than one response so total percentage is over 100.

With the business model described above it was important to learn if participants would continue into a degree program at the university. Figure 3 presents the results of the survey question "If you successfully complete this course, you may be eligible to receive credit towards an MBA or Engineering master's degree. Would you like to be contacted with more information about these programs?" 


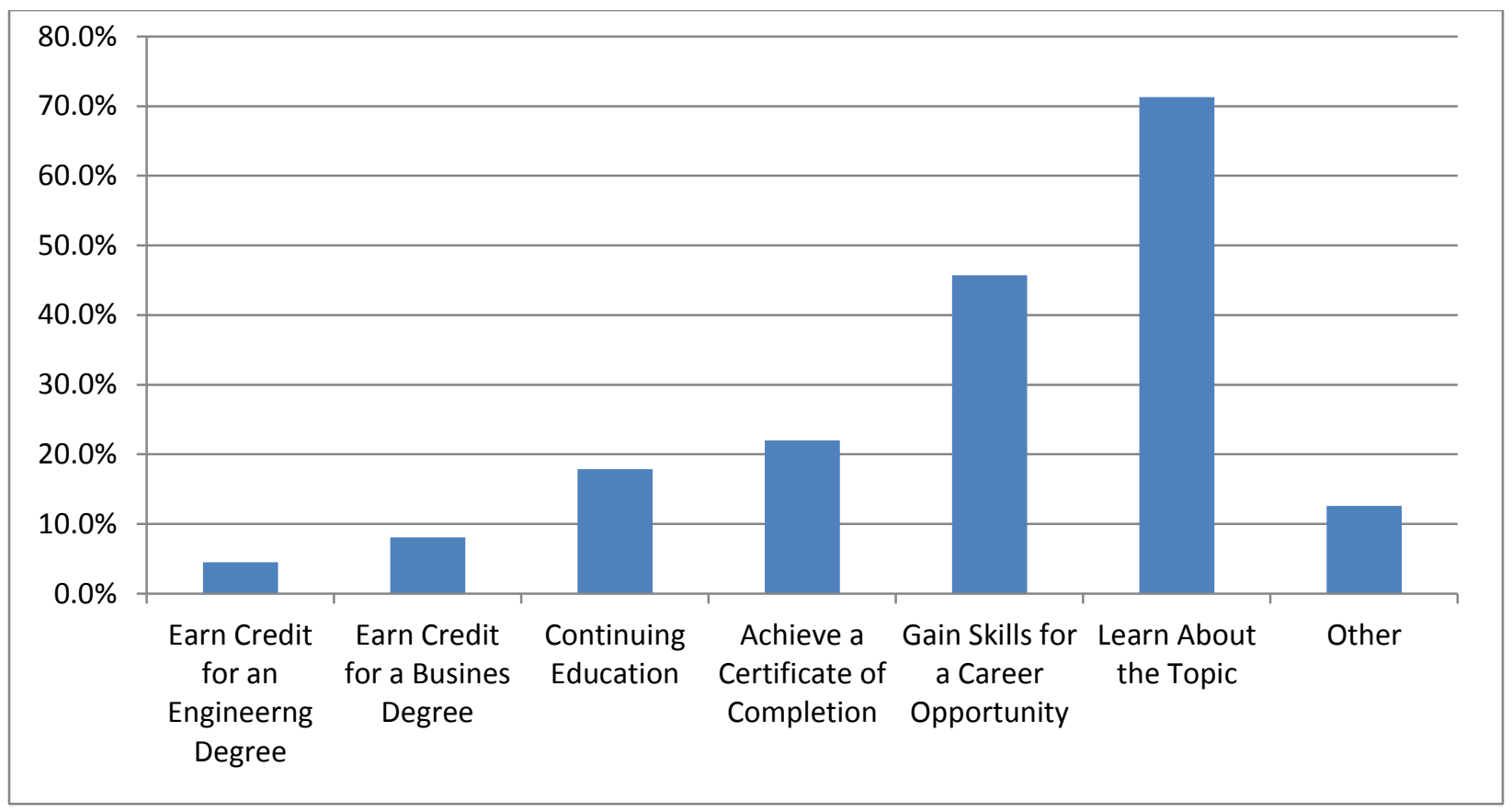

Figure 2 Participants Reasons for Participation in the MOOC

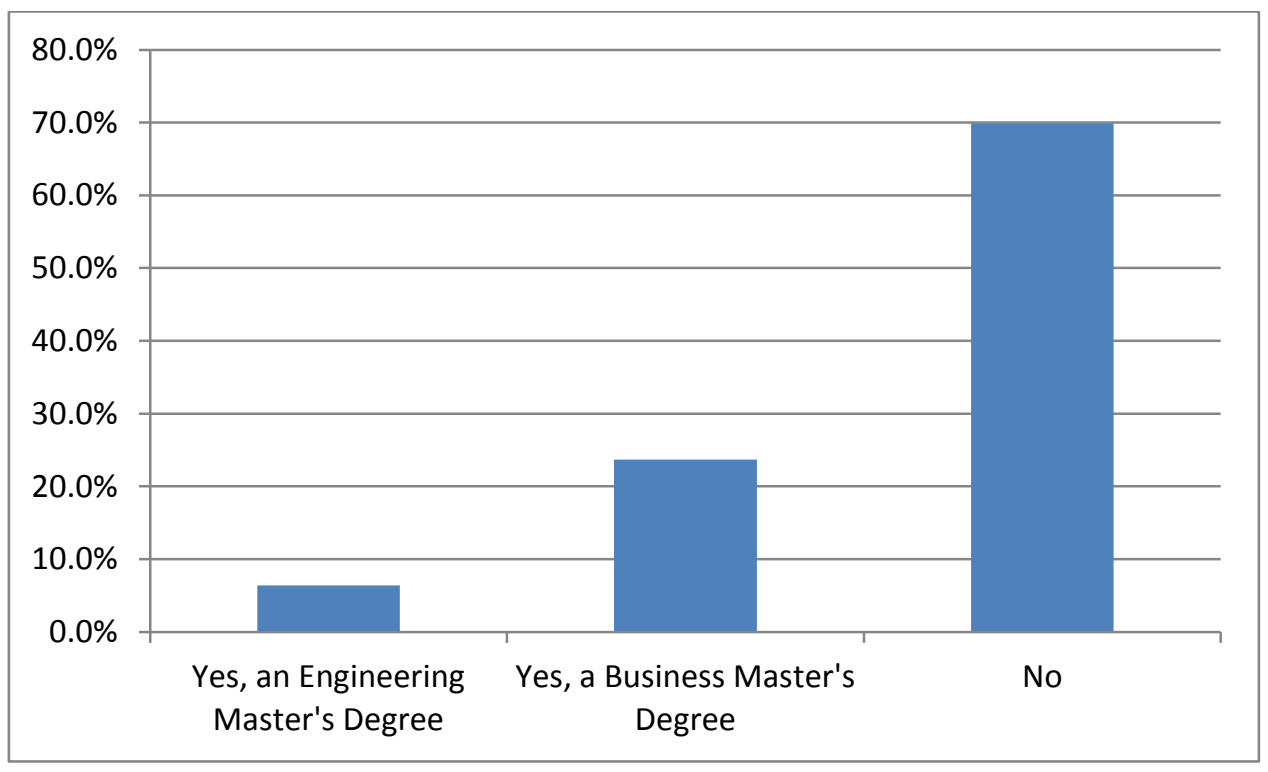

Figure 3 Participants Interest in Graduate Program

Participant's responses to "Would you recommend this course or other University MOOCs to a friend?" are shown in Figure 4. 


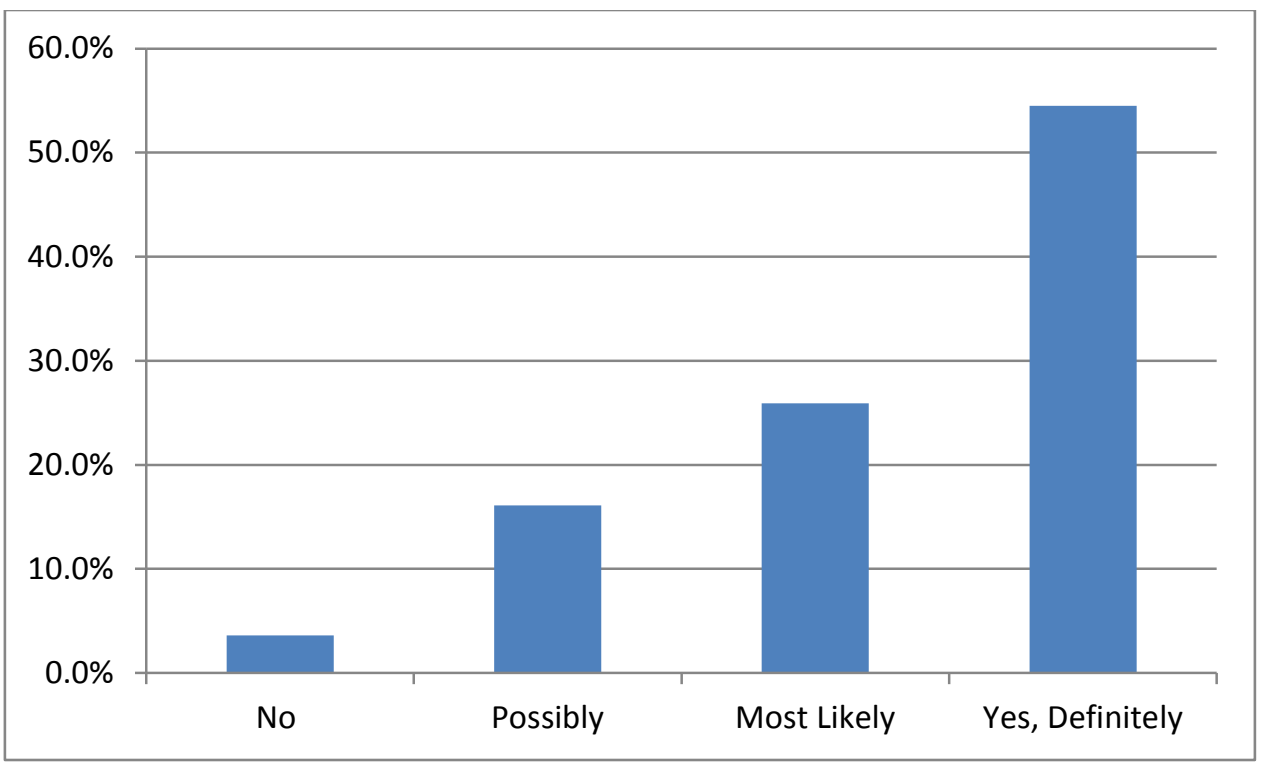

Figure 4 Participants Willingness to Recommend Course

Figure 5 illustrates the number of individuals participating in the weekly quizzes and the average score of those who took the quiz.

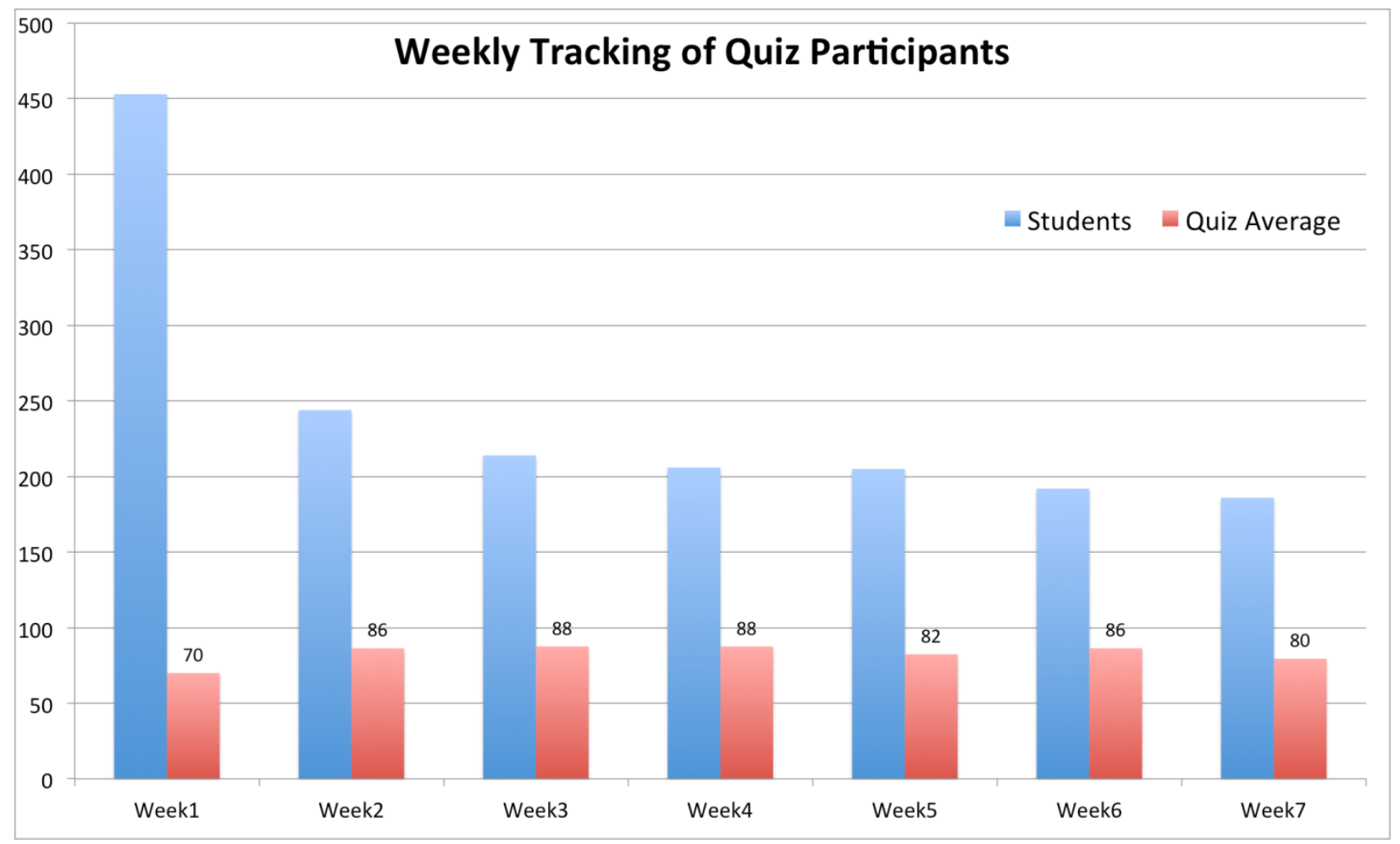

Figure 5 Average Score and Number of Students Taking Quiz 


\section{Results and Lessons Learned}

Based on quiz participation, the MOOC had a completion rate of $8 \%$ which is double the rate reported for most MOOCs ${ }^{8}$. Of those participating in the MOOC, 179 students had a $75 \%$ or better on the quizzes and earned a certificate which was emailed to them. These students had the option to pay to have a printed version of the certificate mailed to them; 40 students chose this option.

Thirty eight participants were interested in a graduate business degree and supplied information while twelve participants were interested in a graduate engineering degree. All were contacted by email or phone. As of the writing of the paper (three montha after the course end date), one MOOC participant has applied to and been accepted to the Master of Engineering program and another participant has an application in process for the MBA program.

Through the process of developing and offering the MOOC, the colleges gained significant insight into the challenges and opportunities associated with the technology and pedagogy associated with MOOCs. In particular:

- There are a variety of reasons to offer MOOCs including: marketing / organizational awareness, outreach, providing professional development, support enrollment in "traditional" programs, etc. It is imperative that the goal(s) be clearly established early so that appropriate decisions regarding design and development can be made which support the goals.

- Very careful attention to content management minimizes issues when the course is offered. Video accessibility issues need to be carefully planned and managed.

- The visibility and positive attention generated for the University was greater than anticipated. The value of this is hard to measure but is likely to have impacts broader than online courses and programs.

- MOOCs can be a substantive method for building relationships with alumni and strategic business partners. The content and learning experiences can provide professional development opportunities and become a source of "value added" from the university.

- While offering a MOOC can accomplish the goals identified above, colleges should have a plan and strategy regarding additional courses and / or online content that will be made available to the general public. If there is only one offering, this will limit the impact and potential positive outcomes.

- The MOOC to Degree strategy does generate interest in the course and college programs. The efficacy of the business model is sound but has not yet yielded desired results.

The MOOC will be offered again in the fall of 2014. The colleges and university are building on the results and lessons learned to thoughtfully move forward with other initiatives that utilize open, online content. 


\section{Bibliography}

1. Pappano, L. 2012. The Year of the MOOC. New York Times. November 2, 2012. Available at http://www.nytimes.com/2012/11/04/education/edlife/massive-open-online-courses-are-multiplying-at-a-rapidpace.html?pagewanted=all\&_r=0

2. Anderson, T., \& McGreal, R. (2012). Disruptive Pedagogies and Technologies in Universities. Journal Of Educational Technology \& Society, 15(4), 380-389.

3. Daniels, J. 2012. Making Sense of MOOCs: Musings in a Maze of Myth, Paradox and Possibility. Journal of Interactive Media in Education http://jime.open.ac.uk/2012/18

4. The Chronicle of Higher Education. MOOC Madness. January 3, 2013. http://chronicle.com/section/OnlineLearning/623/

5. The Economist Newspaper Limited. 2013. The attack of the MOOCs. Jul 20, 2013. Available at http://www.economist.com/news/business/21582001-army-new-online-courses-scaring-wits-out-traditionaluniversities-can-they

6. Rutz, E. 2011. Lessons Learned Offering a Combined BS Engineering (with Cooperative Education) and MBA. Proceedings of the ASEE Annual Meeting. Vancouver, B.C. Canada.

7. Teacher Stream. 2009. Mastering Online Discussion Board Facilitation, a Resource Guide. Available at http://www.edutopia.org/pdfs/stw/edutopia-onlinelearning-mastering-online-discussion-board-facilitation.pdf

8. New York Times. 2013. "After Setbacks, Online Courses Are Rethought”. Published 12/10/13

http://www.nytimes.com/2013/12/11/us/after-setbacks-online-courses-are-rethought.html? r=1\& 